\title{
The Overexpression of Folate Receptors in Gynecologic Oncology - a Diagnostic and Therapeutic Approach
}

\author{
RĂZVAN POPOVICI ${ }^{1}$, ALEXANDRU CĂRĂULEANU' ${ }^{1}$, TUDOR IOAN LAZAR ${ }^{1}$, \\ ANTONETA DACIA PETROAIE ${ }^{2}$, ALEXANDRA PANGAL ${ }^{1}$, MIHAELA GRIGORE ${ }^{1 *}$, IRINA ESANU $^{3}$ \\ 1 "Grigore T. Popa" University of Medicine and Pharmacy "Grigore T. Popa", Faculty of Medicine, Mother and child Care \\ Department, \\ 16 Universitatii Str., 700115, Iasi, Romania \\ 2"Grigore T. Popa" University of Medicine and Pharmacy"Grigore T. Popa", Faculty of Medicine, Family Medicine \\ Department, 16 Universitatii Str., 700115, Iasi, Romania \\ "Grigore T. Popa" University of Medicine and Pharmacy"Grigore T. Popa", Faculty of Medicine, Internal Medical \\ Department, 16 Universitatii Str., 700115, Iasi, Romania
}

Since the discovery of the overexpression of alpha folate receptors $(\alpha-F R)$ in different types of epithelial origin cancers, the arising implications in diagnosis, prognosis and therapy have been thoroughly studied. The $\alpha-F R$ is a glycosylphosphatidylinositol-anchored protein with high affinity for 5-methyltetrahydrofolate, the predominant plasma folate. The expression of FR in healthy cells is found to be only on the apical surface, but the expression in numerous carcinomas of epithelial origin is 100-300 times higher than on healthy cells and it is in the order of 1-10 million receptor copies per cell. Due to the increased expression of $\alpha-F R$ in epithelial tumor cells, it has been emphasized that this receptor could represent a useful target for the development of new and selective anticancer drugs. For targeted delivery to FR expressing cells, it is involved the covalent linkage of folate to a variety of molecules, including chemotherapy or imaging agents. Exploiting the overexpression of $\alpha$-FR in cervical dysplasia and cervical cancer, a new, cost effective and high sensitivity screening test has been developed.

Keywords: folate receptor, gynecologic oncology, folate receptor-mediated staining procedures, cervical cancer screening.

Folic acid represents an essential vitamin highly involved in one-carbon transfer processes mediated by enzyme systems involved in DNA synthesis and methylation, by donating "methyl" groups(1). In normal conditions, folate uptake occurs mostly by an ATP-dependent low-affinity and high-capacity reduced folate carrier. In conditions of limited folate supply, the uptake occurs mainly via folate receptor mediated endocytosis $(2,3)$. In vitro and in vivo studies have stated that the expression of alpha folate receptor $(\alpha-\mathrm{FR})$ allows epithelial tumor cells to proliferate even under conditions of limited folate supply, leading to $\alpha$-FR expression, which can be considered as an acquired marker of tumor cell proliferation, tumor biology and patient prognosis $(2,4)$. The FRs expression in normal tissue is limited and kidneys are the most important site of physiological FR-expression. Recent studies have reported a variable expression of alpha FRs in carcinomas of the ovary and endometrium, non-small cell lung adenocarcinoma, clear cell renal carcinoma, colorectal carcinoma, breast carcinoma, high grade cervical dysplasia, cervical cancer $(5,6)$. The correlation of tumor stage and survival rate in ovarian, endometrial, and lung cancers with the levels of $\alpha$-FR expression has been suggested by several studies. (7).

\section{The alpha folate receptor}

The folate receptors are divided in 4 isoforms (alpha, beta, gamma and delta) $(1,2)$. $\alpha$-FR, the most studied folate receptor, is a glycosylphosphatidylinositol-anchored protein with high affinity (KDB1nM) for 5-methyltetrahydrofolate, the predominant plasma folate. At tissular level the $\alpha$-FR has a limited expression on the apical surfaces of a subset of polarized epithelial cells in the parotid, kidney, lung, thyroid, and breast. $(2,4)$

The $\alpha$-FR is the most widely expressed of all the FR isoforms and it has the most potential for targeted cancer therapy. The expression in numerous carcinomas of epithelial origin is 100-300 times higher than on healthy cells and it is in the order of 1-10 million receptor copies per cell (8-10). Most healthy cells use the reduced folate carrier in order to uptake

*email: mihaela.grigore@edr.ro 
the folate and thus the expression and distribution of $\alpha$-FRs in non-cancerous tissue is largely confined to cells crucial for embryonic development. The expression of FR $\alpha$ in healthy cells is found to be only on the apical surface, prohibiting, in this manner, the exposure of this receptor to folates found in circulation and cytotoxic agents administered parenterally, as intercellular junctions impede small molecules from crossing the epithelium. $(9,11)$

\section{Targeting the $\alpha$-FR for chemotherapy delivery in ovarian cancer}

Ovarian cancer is the third most common gynecological malignancy and the leading cause of death from gynecological cancer in the industrialized nations.(12).

The high systemic toxicity of cytostatic drugs led the way in developing the targeted delivery into the tumor cells as a desired goal in modern cancer chemotherapy (13-16). The antitumor pro-drugs with receptor-affinity ligands are absorbed into the cells using tumor-associated receptors. Due to the increased expression of $\alpha$-FR in epithelial tumor cells, it has been emphasized that this receptor could represent a useful target for the development of new and selective anticancer drugs $(17,18)$.

There are currently many studies available which demonstrate, using cell lines and xenograft, an increased activity, enhanced antitumor efficacy and reduced toxicity of folate receptor targeted drug conjugates compared to no targeted controls. $(19,20)$

The prognostic and predictive significance of FR $\alpha$ overexpression has been less intensively analyzed and the results remain controversial. Due to the differences in tumor biology, it has been observed that the survival rate and the association of FR $\alpha$ expression is very different and highly dependable to the histologic and gender subtypes. (21-25). Recently, an analysis of tissue microarray of ovarian cancer tumor samples found that FR expression in high-grade serous ovarian carcinoma was associated with increased overall survival in the first 2 years following diagnosis [48]. In clear-cell carcinoma it has been noted a decreased progression-free survival interval associated with FR expression. (26) As a result of these data, further analyses should be prospectively investigated in clinical trials.

At present, there are in clinical trials two main strategies of FR-targeted therapy: folate conjugates and monoclonal antibodies (mAbs). (27-31) The development of antifolates that selectively target the FR and a combinatorial strategy is currently taken in consideration.(32). One example is the novel FR $\alpha$-targeted thymidylate synthase inhibitor, BGC 945 (ONX-0801), which is selectively transported into FR $\alpha$-overexpressing tumors, resulting minimal toxicity to healthy tissue (33). Exploiting the FR as a diagnostic and therapeutic target offers numerous advantages (30). Firstly, the location of the FR $\alpha$ on the luminal surface of epithelial cells in most proliferating non-tumor tissues make it inaccessible to circulation. By the contrary, in malignant tissue, the FR $\alpha$ is expressed all over the cell and is accessible to the circulation. Secondly, FR has the ability to bind to folic acid which is a small molecule that can rapidly penetrate solid tumors and available to chemical conjugation with other molecules. By the FR-mediated endocytic pathway, the folate conjugate is bound to FR and is internalized into the cell then after the FR $\alpha$ is rapidly recycled to the cell surface. Taking in consideration all these factors, it can be all emphasized the potential role of FR $\alpha$ in the diagnosis and treatment of specific tumor types. (30-33)

For targeted delivery to FR expressing cells, it is involved the covalent linkage of folate to a variety of molecules, including chemotherapy or imaging agents. The process of endocytosis is often described as a 'molecular Trojan horse' (34).

In case of drug-resistant and drug-sensitive cancer cell lines, Seitz et al. have developed a highly potent nextgeneration folate-taxoid. This folate-taxoid conjugate incorporates a folic acid targeting a highly potent taxoid SB-T1214, which is a derivative of the chemotherapeutic drug Taxol. Similar to vintafolide, it possesses a self immolative disulfide linker, and a hydrophilic PEGylated dipeptide spacer (Fig. 1). (35)

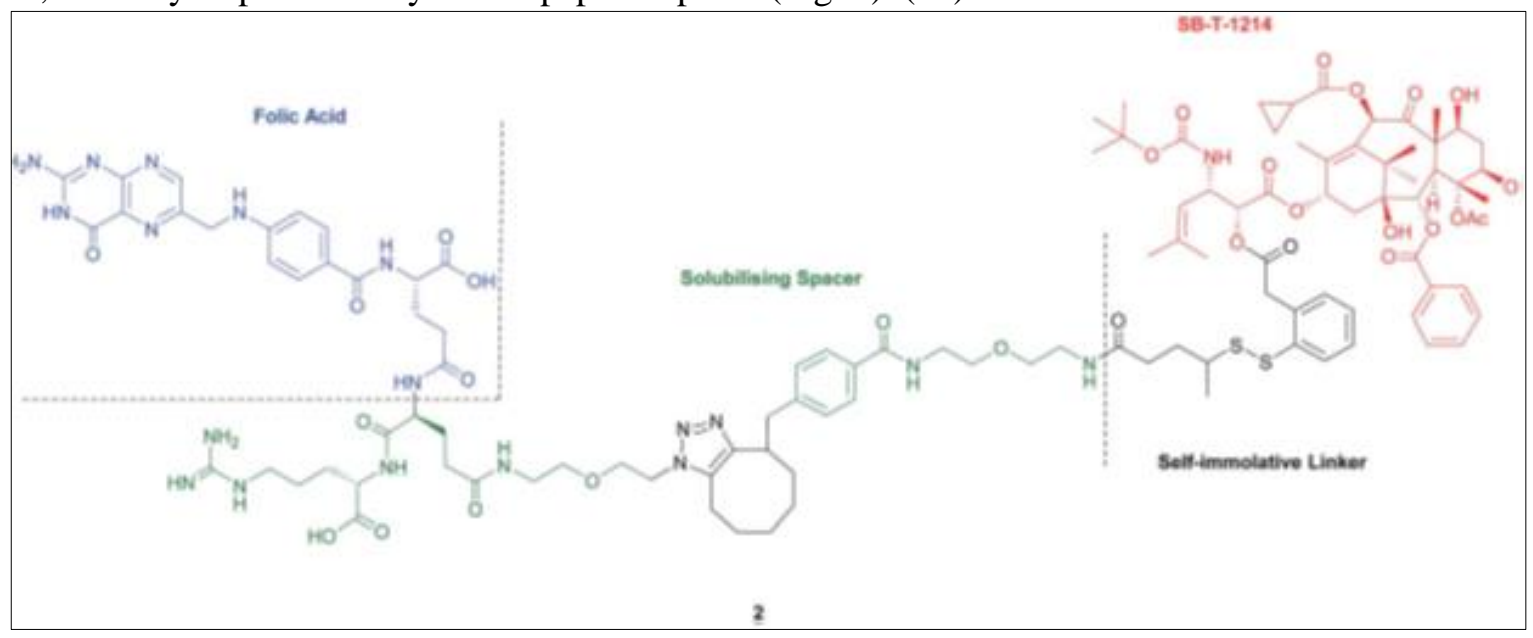

Fig. 1. Structure of the folate-taxoid conjugate 2 developed by Seitz et al. (35) 


\section{The use of folate receptor-mediated staining procedures for early diagnosis of cervical epithelial cancer and high grade dysplasia}

Cervical cancer represents the third most common cancer in women worldwide and the first in terms of incidence and mortality in Romania. (36)

The Papanicolaou test (Pap smear) and/or human papilloma virus (HPV) DNA assay represent, in the most of developed countries, the golden standard for the screening of the cervical cancer. Based on epidemiological studies, the women with folate deficiency have an increased risk of HPV infection and that high folate concentration in cervical epithelial tissue is associated with persistent HPV infection. (37) Aberrant methylation of HPV DNA and promoter hypermethylation of selected host tumor suppressor genes and genes controlling apoptosis are involved directly in persistent high-risk HPV infection.(38) It has been found that higher rate of methylation of certain host promoter genes is associated with higher grade of cervical intra-epithelial neoplasia (CIN).(37) The natural progression from high-grade dysplasia to invasive squamous cell carcinoma is related to the synergistic effect of low serum folate concentration, persistent HPV infection and promoter hyper-methylation of specific tumor suppressor genes. Using Hela cell line expressing high density of FR $\alpha$, it has been demonstrated that the downregulation of FR $\alpha$ by mRNA silencing can inhibit cancer cell proliferation and, in turn, promote apoptosis. (39)

A folate receptor staining solution (FRS) is composed of reduced methylene blue (MB)-folic acid conjugate, dimethyl sulfoxide, ascorbic acid and trace amount of folic acid. Naturally, the FRS has a light brown color. When the solution is applied to a FR $\alpha$ overexpressed cervical epithelia, folic acid binds to FR $\alpha$, triggering a folate receptor-mediated endocytosis of reduced MB-folic acid conjugate. In the endosome reduced MB and folic acid dissociates from FR $\alpha$ and in the cytoplasm, reduced MB (colorless) is converted to oxidized MB (blue) by intracellular oxygen reactive species (ROS). The formation of intracellular ROS is triggered by iron overload in cancerous cells. (40) Upon the amount of intracellular ROS, intra- and extracellular $\mathrm{pH}$ value, the redox status of MB varies, determining the color of the FRS solution. The color changes of the FRS solution caused by MB oxidation can be detected by two cotton swabs: one placed on the ectocervix and the other inserted inside the cervical canal. The color of the swabs changes as follows: blue, bluish black or black indicates the presence of abnormal cervical lesions (>CIN2), no change in color (light brown) or a color change to green is indicative of normal and/or noncancerous cervical epithelia, such as chronic inflammation $(40,41)$.

The staining test is quick and easy to perform. It does not require sophisticated laboratory technology and experienced pathologists for interpretation. Compared to the Pap smear and HPV test, the folate staining test enables clinicians to obtain the results immediately (within 60 seconds). This offer the clinicians the advantage of making fast decisions, an appropriate patient management, facilitating as well the patient compliance with follow-up procedures. Due to its advantage of rapid visualization of abnormal cervical lesions (CIN2+), the test is cost-effective and health care professionals can make cervical cancer screening accessible and less time consuming $(41,42)$.

There are several studies available, up to this moment, regarding the efficacy of folate receptor staining test in the detection of high grade dysplasia and cervical cancer.

$\mathrm{Li}, 2017$, in a study comprising 14344 women obtained the following results regarding the feasibility of staining procedures vs. cervical cytology: folate receptor staining had a moderate agreement with cytology threshold at ASC-H ( $\kappa$ value $=0.52$ ), but had poor agreement with cytology threshold at ASCUS ( $\kappa$ value $=-0.15$ ). Although cytology threshold at ASCUS had

higher than staining procedure for CIN2+ $(99.0 \%$ vs $85.7 \%, P=0.001)$, there was no significant difference between them for CIN3+ $(98.5 \%$ vs $89.2 \%, P=0.07)$. (40)

$\mathrm{Lu}, 2015$, evaluated the sensibility, specificity, negative and positive predictive value(NPV, PPV) of folate receptor mediated staining test vs. thinprep cytology test for cervical dysplasia and cervical cancer. The sensitivity and specificity were $87.72 \%$ and $40.18 \%$, with accuracy of $56.21 \%$. PPV and NPV values were $42.74 \%$ and $86.54 \%$. Youden's index was 0.28 , and odds ratio and positive likelihood ratio were 9.63 and 4.63 respectively. Overall, folate receptor mediated staining test has high values of sensitivity, specificity and Youden index. (42)

\section{Conclusions}

The overexpression of alpha folate receptors in epithelial origin gynecologic cancers has a high diagnostic and therapeutic significance. Targeting the folate receptors for a proper delivery of chemostatic agents confers new opportunities in the treatment of FR positive tumors, at this time especially in ovarian cancer. The FR plays an important role in cancer development and progression, further research is necessary in order to obtain a better refinement in patient selection and identification of new therapeutic combinations. Folate receptor mediated staining test for early diagnosis of cervical dysplasia and cervical cancer is a quick, cost-effective method with high sensitivity and sensibility. 


\section{References}

1. ANTONY AC: The biological chemistry of folate receptors. Blood 79: 2807-2820, 1992.

2. ANTONY AC: Folate receptors. Annu Rev Nutr16: 501-521, 1996.

3. BRZEZINSKA A, WINSKA P and BALINSKA M: Cellular aspects of folate and antifolate membrane transport. ActaBiochim Pol 47:735-749, 2000.

4. ELNAKAT H AND RATMAN M: Distribution, functionality and gene regulation of folate receptor isoforms: implications in targeted therapy. Adv Drug Deliv Rev 56: 1067-1084, 2004.

5. KAMEN BA AND SMITH AK: A review of folate receptor alpha recycling and 5-methyltetrahydrofolate accumulation with emphasis on cell models in vitro. Adv Drug Del Rev 56: 1085-1097, 2004.

6. KRATZ F, MULLER Y, RYPPA C AND WARNECKE A: Prodrug strategies in cancer chemotherapy. Chem Med Chem3: 20-53, 2008.

7. SUZUKI R, RAO P AND SASAGURI S: Current status and future of target-based therapeutics. Curr Cancer Drug Targets 7(3): 273-284, 2007.

8. HISS D. Optimizing molecular-targeted therapies in ovarian cancer: the renewed surge of interest in ovarian cancer biomarkers and cell signaling pathways. J Oncol 2012; 2012: 737981.

9. ZWICKE GL, MANSOORI GA, JEFFERY CJ. Utilizing the folate receptor for active targeting of cancer nanotherapeutics. Nano Rev 2012 Dec 7 [epub ahead of print], doi: 10.3402/nano.v3i0.18496.

10. GONEN N, ASSARAF YG. Antifolates in cancer therapy: structure, activity and mechanisms of drug resistance. Drug Resist Updat 2012; 15: 183-210.

11. ELNAKAT H, RATNAM M. Role of folate receptor genes in reproduction and related cancers. Front Biosci 2006; 11: 506-519. Volume 26 | No. 10 | October 2015 doi:10.1093/annonc/mdv250 Annals of Oncology reviews

12. REID BM, PERMUTH JB, SELLERS TA. Epidemiology of ovarian cancer: a review. Cancer Biol Med. 2017;14(1):9-32. doi:10.20892/j.issn.2095-3941.2016.0084

13. TWU C, HAN ES. Clinical utility of targeted treatments in the management of epithelial ovarian cancer. Biologics 2012; 6: 233-244.

14. MENDELSOHN J. Personalizing oncology: perspectives and prospects. J Clin Oncol 2013; 31(15): 1904-1911.

15. KATSNELSON A. Momentum grows to make 'personalized' medicine more 'precise'. Nat Med 2013; 19: 249.

16. TIAN Q, PRICE ND, HOOD L. Systems cancer medicine: towards realization of predictive, preventive, personalized and participatory (P4) medicine. J Intern Med 2012; 271: 111-121.

17. MERIC-BERNSTAM F, MILLS GB. Overcoming implementation challenges of personalized cancer therapy. Nat Rev Clin Oncol 2012; 9: 542548.

18. GONZALEZ DE CASTRO D, CLARKE PA, AL-LAZIKANI B, WORKMAN P. Personalized cancer medicine: molecular diagnostics, predictive biomarkers, and drug resistance. Clin Pharmacol Ther 2013; 93: 252-259.

19. PALUMBO MO, KAVAN P, MILLER WH Jr et al. Systemic cancer therapy: achievements and challenges that lie ahead. Front Pharmacol 2013; 4: 57.

20. KEEFE DM, BATEMAN EH. Tumor control versus adverse events with targeted anticancer therapies. Nat Rev Clin Oncol 2012; 9: 98-109.

21. DESPIERRE E, LAMBRECHTS S, LEUNEN K et al. Folate receptor alpha (FRA) expression remains unchanged in epithelial ovarian and endometrial cancer after chemotherapy. Gynecol Oncol 2013; 130: 192-199.

22. CRANE LM, ARTS HJ, van OM et al. The effect of chemotherapy on expression of folate receptor-alpha in ovarian cancer. Cell Oncol 2012; 35: 9-18.

23. TOFFOLI G, RUSSO A, GALLO A et al. Expression of folate binding protein as a prognostic factor for response to platinum-containing chemotherapy and survival in human ovarian cancer. Int J Cancer 1998; 79: 121-126.

24. BREMER RE, SCOGGIN TS, SOMERS EB et al. Interobserver agreement and assay reproducibility of folate receptor alpha expression in lung adenocarcinoma: a prognostic marker and potential therapeutic target. Arch Pathol Lab Med 2013; 137(12): 1747-1752.

25. HARTMANN LC, KEENEY GL, LINGLE WL et al. Folate receptor overexpression is associated with poor outcome in breast cancer. Int J Cancer 2007; 121: 938-942.

26. KOBEL M, MADORE J, RAMUS SJ et al. Evidence for a time-dependent association between FOLR1 expression and survival from ovarian carcinoma: implications for clinical testing. An Ovarian Tumour Tissue Analysis consortium study. Br J Cancer 2014; 111(12): 2297-2307.

27. PRIBBLE P, EDELMAN MJ. EC145: a novel targeted agent for adenocarcinoma of the lung. Expert Opin Investig Drugs 2012; $21: 755-761$.

28. REDDY JA, DORTON R, WESTRICK E et al. Preclinical evaluation of EC145, a folatevinca alkaloid conjugate. Cancer Res 2007; 67: 44344442 .

29. ARMSTRONG DK, WHITE AJ, WEIL SC et al. Farletuzumab (a monoclonal antibody against folate receptor alpha) in relapsed platinumsensitive ovarian cancer. Gynecol Oncol 2013; 129: 452-458.

30. THOMAS A, MALTZMAN J, HASSAN R. Farletuzumab in lung cancer. Lung Cancer 2013; 80: 15-18.

31. WEN Y, GRAYBILL WS, PREVIS RA et al. Immunotherapy targeting folate receptor induces cell death associated with autophagy in ovarian cancer. Clin Cancer Res 2015; 21: 448-459.

32. GIBBS DD, THETI DS, WOOD N et al. BGC 945, a novel tumor-selective thymidylate synthase inhibitor targeted to alpha-folate receptoroverexpressing tumors. Cancer Res 2005; 65: 11721-11728.

33. KAMEN BA, SMITH AK. Farletuzumab, an anti-folate receptor alpha antibody, does not block binding of folate or anti-folates to receptor nor does it alter the potency of anti-folates in vitro. Cancer Chemother Pharmacol 2012; 70: 113-120.

34. LEAMON CP, Reddy JA. Folate-targeted chemotherapy. Adv Drug Deliv Rev 2004; 56: 1127-1141.

35. J. D. SEITZ, J. G. VINEBERG, E. HERLIHY, B. PARK, E. MELIEF AND I. OJIMA, Bioorg. Med. Chem., 2015, $23,2187-2194$.

36. TATARU AL, FURAU G, AFILON J, et al. The Situation of Cervical Cancers in the Context of Female Genital Cancer Clustering and Burden of Disease in Arad County, Romania. J Clin Med. 2019;8(1):96. Published 2019 Jan 15. doi:10.3390/jcm8010096

37. FLATLEY JE, MCNEIR K, BALASUBRAMANI L et al. Folate status and aberrant DNA methylation are associated with HPV infection and cervical pathogenesis. Cancer Epidemiol Biomarkers Prev 2009; 18: 2782-9.

38. WILLIAMS VM, FILIPPOVA M, SOTO U, Duerksen-Hughes PJ. HPV-DNA integration and carcinogenesis: putative roles for inflammation and oxidative stress. Future Virol 2011;6: 45-57.

39. BAI LX, DING L, JIANG SWEt al. Down-regulation of FRalpha inhibits proliferation and promotes apoptosis of cervical cancer cells in vitro. Asian Pac J Cancer Prev 2014; 15:5667-72.

40. LI, D. , CHEN, L. , WANG, H. , YANG, H. , DAI, Y. , YU, C. and DONG, Y. (2017), Clinical application of a rapid cervical cancer screening method: Folate receptor-mediated staining of cervical neoplastic epithelia. Asia-Pac J Clin Oncol, 13: 44-52. doi:10.1111/ajco.12573 
41. CHEN C, YANG Z, LI Z, LI L. Accuracy of several cervical screening strategies for early detection of cervical cancer: a meta-analysis. Int J Gynecol Cancer 2012; 22: 908-21.

42. LU MH, HU LY, DU XX, YANG M, ZHANG WY, HUANG K, LI LA, JIANGSF, LI YL. An special epithelial staining agents: folic acid receptor-mediated diagnosis (FRD) effectively and conveniently screen patientswith cervical cancer. Int J Clin Exp Med 2015;8(5):7830-6.

Manuscript received: 12.12 .2019 